\title{
Macrophage Response to UHMWPE Submitted to Accelerated Ageing in Hydrogen Peroxide
}

\author{
Magda F.G. Rocha ${ }^{1}$, Alexandra A.P. Mansur ${ }^{1}$, Camila P.S. Martins ${ }^{2}$, Edel F. Barbosa-Stancioli ${ }^{2}$ and \\ Herman S. Mansur*,1
}

${ }^{I}$ Department of Metallurgical and Materials Engineering, Laboratory of Biomaterials and Tissue Engineering, Federal
University of Minas Gerais, Av. Antônio Carlos, 6627, 31.270-901, Belo Horizonte, Brazil

${ }^{2}$ Department of Microbiology, Institute of Biological Science, UFMG, Brazil

\begin{abstract}
Ultra-high molecular weight polyethylene (UHMWPE) has been the most commonly used bearing material in total joint arthroplasty. Wear and oxidation fatigue resistance of UHMWPE are regarded as two important properties to extend the longevity of knee prostheses. The present study investigated the accelerated ageing of UHMWPE in hydrogen peroxide highly oxidative chemical environment. The sliced samples of UHMWPE were oxidized in a hydrogen peroxide solution for 120 days with their total level of oxidation (Iox) characterized by Fourier Transformed Infrared Spectroscopy (FTIR). The potential inflammatory response, cell viability and biocompatibility of such oxidized UHMWPE systems were assessed by a novel biological in vitro assay based on the secretion of nitric oxide (NO) by activated murine macrophages with gamma interferon (IFN- $\gamma$ ) cytokine and lipopolysaccharide (LPS). Furthermore, macrophage morphologies in contact with UHMWPE oxidized surfaces were analyzed by cell spreading-adhesion procedure using scanning electron microscopy (SEM). The results have given significant evidence that the longer the period of accelerated aging of UHMWPE the higher was the macrophage inflammatory equivalent response based on NO secretion analysis.
\end{abstract}

Keywords: UHMWPE, prosthesis, macrophage response, polymer oxidation, accelerated aging.

\section{INTRODUCTION}

Ultra-high molecular weight polyethylene (UHMWPE) is a biomaterial which is widely used as part of prostheses that require articulating surfaces, such as knee endoprostheses, due to its excellent mechanical qualities. Approximately one million UHMWPE components are implanted yearly worldwide. Two major problems limit the life of UHMWPE prosthesis: wear and delamination. Both phenomena tend mainly to be the result of the chemical oxidation of polymers [1-6]. Polyethylene wear debris formation continues to be a primary factor in the reduced longevity of total knee replacements [1-3]. Wear can cause the release of particulate material which triggers a macrophage reaction, thus leading to chronic inflammation and osteolysis. On the hand, delamination failure is due to the mechanical stress that macroscopically alters the surfaces [2,6]. It is well-known in the field of biomaterials that surface chemistry plays an important role in the interaction of cells, specifically those cells involved in the inflammatory response. Thus, this aspect must be considered in the applications of UHMWPE [2-4].

Oxidized UHMWPE is an inherent state that exists in UHMWPE components used in total joint replacements. As such, studies that investigate the interaction of particles with cells and tissue should consider the effect of this surface

*Address correspondence to this author at the Department of Metallurgical and Materials Engineering, Laboratory of Biomaterials and Tissue Engineering, Federal University of Minas Gerais, Av. Antônio Carlos, 6627, 31.270-901, Belo Horizonte, Brazil; Tel: +55 31 34091843; Fax: +55 31 34091815; E-mail: hmansur@ demet.ufmg.br chemistry in their models. This effect potentially influences the structural state of the particles, the nature of leachable species and their release rates, the kinetics of the degradation reaction, and the way by which biological elements of the living surroundings act on the implanted material. In other words, cellular interactions are strongly affected by the oxidation state of surfaces [3-6]. It has also been wellestablished in the literature that these UHMWPE components are commonly susceptible to oxidative degradation through the consolidation of the resin at high temperatures and pressures, sterilization by gamma irradiation, storage of the irradiated UHMWPE components, and the implantation environment. The oxidation of UHMWPE components has been linked to changes in the mechanical properties of the material, such as decreased fatigue strength and the production of wear particles around the site of the implant [4]. Until the 1980s, the large majority of researches have focused on investigating the failures of hip prosthesis. Only in recent years some studies in vitro have been reported addressing the chemical oxidation of UHMWPE aiming the knee implants. Yet, the entire degradation mechanism and the kinetics remain unclear. In fact, there are not many reports in the literature that have investigated the accelerated aging process by oxidative chemical solution and the relationship with the actual failure that occurs in UHMWPE prosthesis [5-11].

MTT assay (3-(4,5-Dimethylthiazol-2-yl)-2,5- diphenyltetrazolium bromide) and cell adhesion have commonly been used for the preliminary evaluation of biocompatibility of biomaterials. More recently, nitric oxide (NO), which is a potent signaling molecule secreted by healthy endothelial 
cells, has been used to assess cell activity [12]. NO is a highly reactive, free radical chemical involved in a number of physiological and pathological processes. Macrophages induce the generation of NO, a high level of which could lead to the rejection of a biomaterial [12]. As a result, NO production by macrophages can be examined as an indicator of cell activation by biomaterials [13]. Macrophages play a crucial role in the host defense. They form the first line as a component of the innate immune response, but they also assist in the adaptive immunological system. A prospective biomaterial must undergo extensive in vitro and in vivo tests and should ensure the non-toxicity of the biological host site where it will be applied. Cell-based compatibility assays should be properly conducted as a reliable tool of predicting the biomaterial behavior in vivo and future clinical performance $[12,14]$. It should be highlighted that by using LPS or IFN- $\gamma$ activation of macrophages, one aims to cause macrophage activation along the classical or type I pathway (and not along the alternative type II pathway). Classical activation leads to induction of iNOS (inducible nitric oxide synthase), which is able to produce NO, resulting the production of nitrogen radical, then impart these macrophage an ability to kill intracellular microbes [14]. Since the pioneering work from Santavirta and co-workers [15], despite the large number of works in recent years that seem to indicate a satisfactory behavior of UHMWPE for bearing applications $[16,17]$, further research needs to be carried out in order to properly predict the lifetime of these prostheses after implantation [5-11].

In the present study, an accelerated ageing by oxidative degradation of UHMWPE in hydrogen peroxide solution was performed and the macrophage response by NO secretion was analyzed to verify the influence of chemical surfaces on the inflammatory process.

\section{EXPERIMENTAL SECTION}

\subsection{Materials}

The polyethylene used in this work was ram-extruded UHMWPE bar stock GUR 1020, of commercial grade and approved for surgical implants (ISO 5834-2/2005), and was kindly donated by Ticona Engineering Polymer (USA). The typical properties of UHMWPE as provided by the supplier are listed in Table $\mathbf{1 .}$

\subsection{Sample Preparation for Accelerated Oxidation Assay}

The bar stock was sectioned with a steel blade into 50 $\mathrm{mm} \times 50 \mathrm{~mm} \times 50 \mathrm{~mm}$ cubic blocks and samples were sliced with thickness ranging from 150 to $250 \mu \mathrm{m}$. All samples were cleaned in an ethanol (P.A., Sigma) and distilled water ultrasound bath, air dried, and submitted to experimental analysis. Non-oxidized samples (triplicates, $\mathrm{n}=3$ ) of UHMWPE ("reference control group") were immersed in 30 $\mathrm{mL}$ of hydrogen peroxide and incubated at $37^{\circ} \mathrm{C}$. The degradation oxidative solution was prepared using 30v/v \% hydrogen peroxide (analytical grade, $\mathrm{H}_{2} \mathrm{O}_{2},>30 \% \mathrm{v} / \mathrm{v}, \sim 8.8$ mol. $L^{-1}$ ), which was replaced every five days to maintain the activity of the solution. This solution replacement was based on the estimated half-life of $\mathrm{H}_{2} \mathrm{O}_{2}$ of approximately seven days at $37^{\circ} \mathrm{C}$. The experimental aging times were monitored at 0 (initial state, reference), 7, 14, 21, 28, 60, and 120 days, and such oxidized samples were referred as UHMWPE-Ox.
Table 1. Material Properties of UHMWPE Bar Stock Based on the Data Sheet from the Manufacturer

\begin{tabular}{|l|l|}
\hline UHMWPE & GUR 1020 \\
\hline Resin type & Ticona \\
\hline \hline Manufacturer & Ram extrusion \\
\hline Manufacturing Method & Annealed \\
\hline Fabricated Form & 5.166 to 5.415 \\
\hline Average molecular wt (molar mass) $\left[\mathrm{g} / \mathrm{mol} \times 10^{6}\right]$ & $66-71$ \\
\hline Crystallinity; DSC, $\left(20^{\circ} \mathrm{C}-160{ }^{\circ} \mathrm{C}\right)[\%]$ & 934 \\
\hline Density [Kg/m $\left.{ }^{3}\right]$ & $>23$ \\
\hline Tensile stress at yield (tensile strength) $[\mathrm{MPa}]$ & $>52$ \\
\hline $\begin{array}{l}\text { Tensile stress at break }[\mathrm{ultimate} \text { tensile strength] } \\
{[\text { MPa] }}\end{array}$ & $>460$ \\
\hline Elongation at break $[\%]$ & $>575$ \\
\hline Young's modulus [MPa] & 137.5 \\
\hline Melting Point DSC, $10 \mathrm{~K} / \mathrm{min}\left[{ }^{\circ} \mathrm{C}\right]$ & -110 \\
\hline Glass Transition Temperature Tg $\left[{ }^{\circ} \mathrm{C}\right]$ & 0.00 \\
\hline $\begin{array}{l}\text { Surface and bulk Oxidation Index; material shelf- } \\
\text { aged } 1 \text { year in air }(\mathrm{ASTM} \text { F } 101-01)\end{array}$ & \\
\hline
\end{tabular}

\subsection{Characterization Techniques}

\subsubsection{Fourier Transform Infrared Spectroscopy (FTIR)}

Fourier Transformed Infrared Spectroscopy (FTIR) spectra were collected in transmission mode with the wavenumber ranging from 4,000 to $400 \mathrm{~cm}^{-1}$ during 64 scans, with $2 \mathrm{~cm}^{-1}$ resolution (Paragon 1,000, Perkin-Elmer, USA). The FTIR spectra were normalized, and major vibration bands were identified and associated with the main chemical groups. The total level of oxidation $\left(\mathrm{I}_{\mathrm{ox}}\right)$ was determined by FTIR according to ISO 5834-2, which has been broadly reported in literature [18-22]. Briefly, this oxidation factor $\mathrm{I}_{\mathrm{ox}}$ is assumed as the peak area at 1,650 $1,850 \mathrm{~cm}^{-1}$ divided by the peak area at $1,370 \mathrm{~cm}^{-1}$. This procedure has given an overall relative uncertainty of $10 \%$.

\subsubsection{Bioactivity and Cell Viability on Oxidized UHMWPE}

\subsubsection{Cell Activity - Nitric Oxide (NO) Production Assay}

As far as biocompatibility is concerned, it is of paramount importance to move beyond standard regular bioactivity methods to properly evaluate UHMWPE samples. Therefore, a novel approach is proposed in this research, where nitric oxide (NO) secretion was stimulated by cytokine (IFN- $\gamma$ ) and other inductive moiety named lipopolysaccharide (LPS) to assess cell activity when in contact with modified polymeric systems. Mice were euthanized by halothane inhalation (approved by the ethics committee of Federal University of Minas Gerais). Next, 7$10 \mathrm{~mL}$ of ice-cold RPMI-1640 medium (Roswell Park Memorial Institute) supplemented with $10 \%$ (v/v) fetal bovine serum (FBS) was injected into their peritoneal 
cavities. Lavage fluids were pooled from several mice and large, peritoneal macrophage cells (line $\mathrm{C} 57 \mathrm{BL} / 6 \mathrm{~J}$ ) were counted on a hemacytometer. Then, $200 \mu \mathrm{L}$ of the medium (RPMI 1640 with $10 \%$ FBS) with cells were seeded in 24well tissue culture plates (Costar) at a density of $1.0 \times 10^{5}$ together with slices of UHMWPE and UHMWPE-Ox samples which had been previously placed (4 replicates of each) on the plate. Negative controls were prepared by adding $200 \mu \mathrm{L}$ of medium (RPMI 1640 with $10 \%$ FBS) without any samples $(n=4)$. In addition, the macrophage cells were stimulated for NO production by adding cytokine IFN$\gamma(120 \mathrm{U} / \mathrm{mL})$ and LPS $(100 \mathrm{ng} / \mathrm{mL})$ to the medium. All plates were then kept in a $37^{\circ} \mathrm{C}$ incubator supplemented with $5 \% \mathrm{CO}_{2}$. Macrophages were allowed to adhere for $48 \mathrm{~h}$, at which point the wells were washed three times with endotoxin-free, phosphate buffered saline (PBS) to rinse away most non-adherent cells. Production of NO was estimated by measuring nitrite levels in the supernatant with a Griess reagent (1:1 ratio of $0.1 \%$ of N-1-naphthylethylenediamine and $1 \%$ sulphanilamide in $5 \%$ phosphoric acid). The Griess reagent was added to $100 \mu \mathrm{L}$ of sample cell supernatant and was incubated at room temperature for 10 min. Absorbance was measured at wavelength $=550 \mathrm{~nm}$ using ASYS EXPERT PLUS spectrometric microplate reader. The absorbance values were converted to their corresponding concentration of NO, which was produced using a standard curve for $\mathrm{NaNO}_{2}$.

\subsubsection{Cell Adhesion-Spreading Assay}

Cell viability was evaluated by spreading and attachment assays in order to examine their morphology, adhesion and spreading behavior. The murine macrophage cells were plated at $1 \times 10^{5}$ density onto the sample slices of UHMWPE and UHMWPE-Ox that were previously placed on microplates (24wells). Cell spreading was observed by scanning electron microscopy (SEM, JEOL/Noran, JSM $6360 \mathrm{LV}$ ). Before microscopy analysis, specimens were fixed with $2 \%$ glutaraldehyde for 16 hours and dehydrated by passing through a series of alcohol solutions (ethanol-water). Then, they were dried in nitrogen flowing reactor for 4 hours and out-gassed in vacuum desiccator for 12 hours. Before examination the samples were sputtered with a thin layer of gold using low deposition rate, and placed at the maximum distance from the target to prevent damaging them. The images were obtained using an accelerating voltage of $10-$ $15 \mathrm{kV}[13]$.

\section{RESULTS AND DISCUSSION}

\subsection{FTIR Spectroscopy - Oxidation}

FTIR spectroscopy was used to characterize the oxidized UHMWPE samples (UHMWPE-Ox). Fig. (1A) presents FTIR spectra from UHMWPE before and after 28, 60, and 120 days of accelerated aging in hydrogen peroxide. The main changes in the FTIR spectra upon the oxidation of polyethylene samples involved the formation of typical products, such as isolated hydroperoxides $\left(3,550 \mathrm{~cm}^{-1}\right)$, hydrogen bonds (hydroxyls at $\left.3,410 \mathrm{~cm}^{-1}\right)$, lactones $(1,860$ $\left.\mathrm{cm}^{-1}\right)$, esters $\left(1,740 \mathrm{~cm}^{-1}\right)$, acids, and ketones $(1,710-1,720$ $\left.\mathrm{cm}^{-1}\right)$. In addition, an increase in the absorbance in the range from 1,400 to $1,180 \mathrm{~cm}^{-1}$, associated with -C-O-C vibrations, and in the range from 800 to $1,100 \mathrm{~cm}^{-1}$, mostly related to unsaturated $\mathrm{C}=\mathrm{C}$ groups. It can be noted in Fig. (1B) the evolution of the strong vibration band related to carbonyl groups with the aging time in hydrogen peroxide solution, as it is the most usual chemical specie formed by polyethylene oxidation. Thus, the FTIR results of UHMWPE samples after the accelerated aging assays have clearly indicated the major bands usually associated with the oxidative degradation of UHMWPE endorsed by the broadly reported literature $[6,10,13,18-22]$.

The spectral regions recommended by ISO 5834-4 (2005) were used to estimate the oxidation degree aiming to conduct a quantitative analysis associated with a more in-depth investigation of the UHMWPE degradation under oxidative stress condition. The curve showed in Fig. (2), based on the overall reaction $\left(\mathrm{I}_{\mathrm{ox}}\right)$, clearly indicated that oxidation of the UHMWPE has taken place, with a slow evolution up to approximately 28 days. Subsequently, a steep rise could be observed up to 120 days of evaluation. These high values of
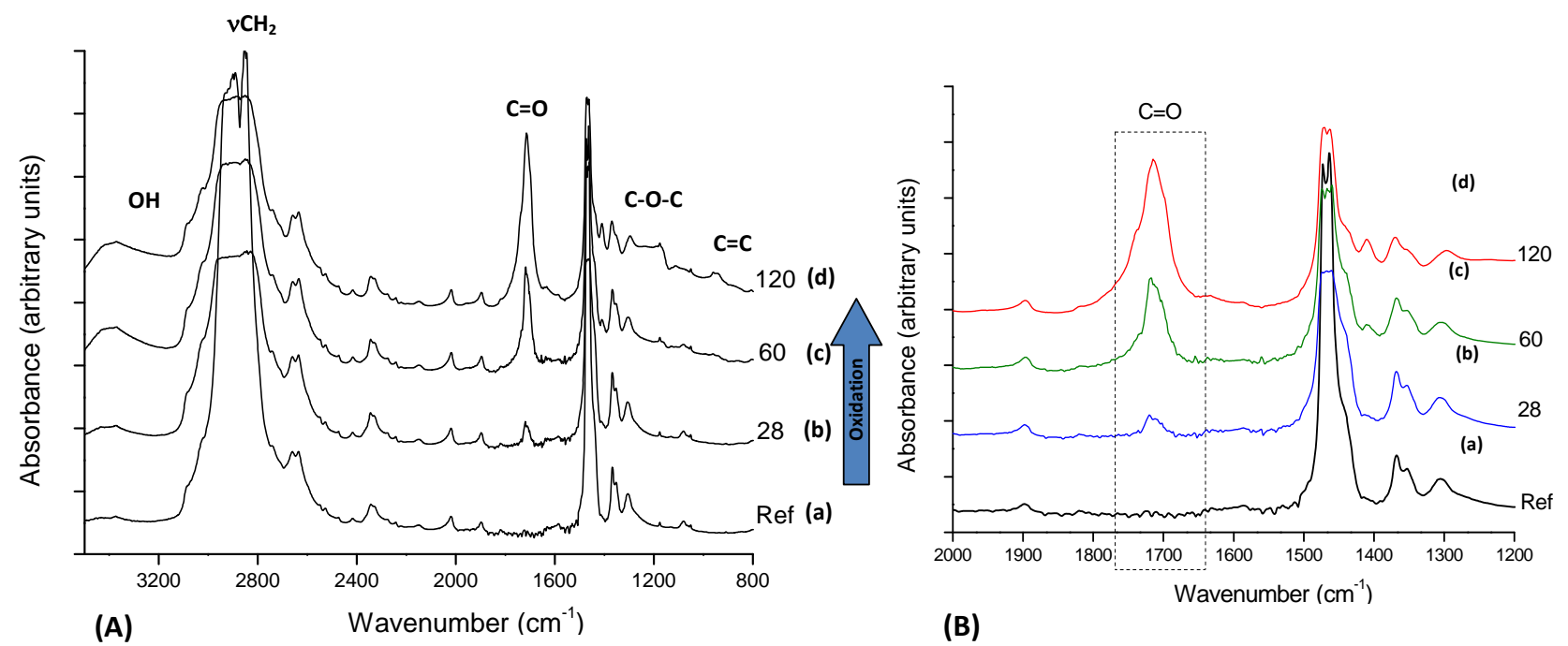

(B)

Fig. (1). (A): FTIR spectra of reference UHMWPE (a) and UHMWPE oxidized for (b) 28 days, (c) 60 days and (d) 120 days; (B) Detail: carbonyl group evolution with aging time. 
$\mathrm{I}_{\mathrm{ox}}$ (typically above 4.0 ) are comparable to those reported in previous researches on retrieved prosthesis after degradation and severe inflammation processes under patient use. Hence, FTIR has proven to be an important tool, not only for investigating UHMWPE degradation, but also for providing relevant information concerning to the peroxide reaction kinetics as an indication for potential prosthesis lifetime behavior.

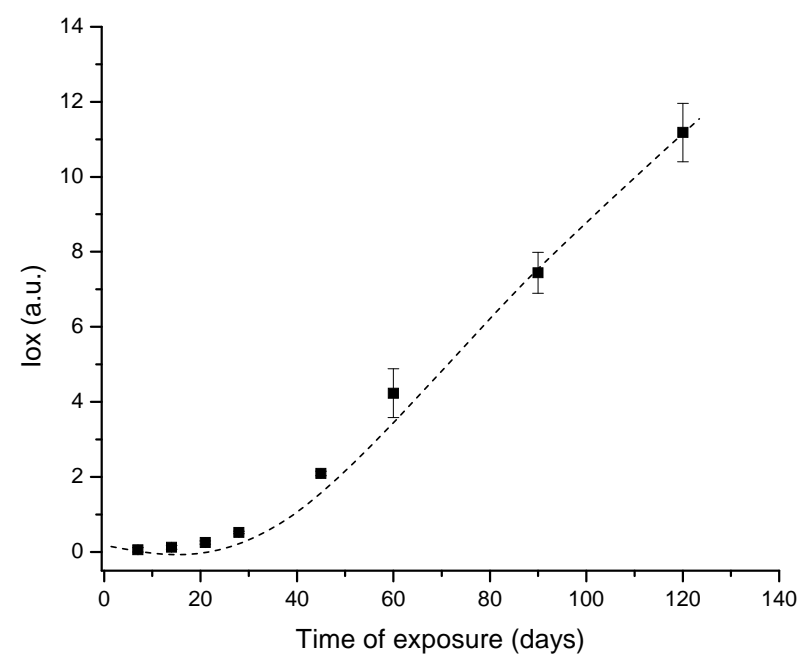

Fig. (2). Evolution of UHMWPE degradation in $\mathrm{H}_{2} \mathrm{O}_{2}$ estimated by FTIR using the Oxidation Index $\left(\mathrm{I}_{\mathrm{ox}}\right)$ at different aging times.

\subsection{Bioactivity and Cell Viability on Oxidized UHMWPE}

\subsubsection{Cell Activity - Nitric Oxide (NO) Production Assay}

The macrophage response versus the oxidation index $\left(\mathrm{I}_{\mathrm{ox}}\right)$ was analyzed to investigate the ability of UHMWPE to induce macrophage activation after polymer surface oxidation submitted to accelerated oxidative. The results are presented in Fig. (3). It could be observed that the macrophage response regarding to the oxidized UHMWPE was relatively unchanged up to the oxidation index value $\left(\mathrm{I}_{\mathrm{ox}}\right)$ of about 4.0 , then a significant increase was verified. This value of $\mathrm{I}_{\mathrm{ox}}$ would represent approximately 50-60 days under accelerated aging solution. It can be observed by combining results from Figs. ( 2 and 3 ) that the $I_{o x}$ was gradually increasing as the aging time was higher up to 120 days. It was somehow expected from the chemical reaction of the polyethylene with peroxide, with a slow rate at the initial stage followed by an accelerated degradation of the polymeric network due to the radicals propagation. On the other hand, in order to understand the macrophage response in the present study it is required a concise background on foreign body reaction from living organism induced by biomaterials. In summary, the interactions at the cellsubstrate interface are mediated by extracellular signals such as cytokines or growth factors that induce changes in the cell substrate adhesion and the extracellular matrix. Macrophages are involved in the host defense and play an important role in immune regulation. They induce generation of nitric oxide, a high level of which could lead to the rejection of a biomaterial during in vivo studies. Cytokines and endotoxin, for instance interferon (IFN) $-\gamma$ and lipopolysaccharide (LPS), respectively, induce the expression of one isoform of nitric oxide synthase (iNOS), which generates high levels of nitric oxide that is cytotoxic or cytostatic to target cells $[12,14]$. Consequently, it is essential to assess the NO production to reliably investigate inflammatory response of systems in contact with living organisms. Nevertheless, one should be aware that is beyond the scope of this study to present an indepth description of the complete macrophage response to cytokines, as they have a rather complex pathway that it not yet understood, but the application of the concept on evaluating polymer based materials [13]. Hence, the results of our study regarding to macrophage behavior when placed in contact to UHMWPE with different degrees of surface oxidation have given an evidence of potential inflammatory response from the living organism by the degradation of the UHMWPE prosthesis surface. It seems that after it has reached a threshold it will most probably cause the prosthesis failure by severe inflammation. The importance of these results is that the biological response to UHMWPE oxidation is correlated to the development of wear particles within the periprosthetic tissue, where they are phagocytosed by macrophages. Eventually, osteoclasts are recruited and/or activated to resorb the bone, thus leading to osteolysis and the loosening of the prosthesis [23]. Several authors [23-25] have reported a direct relationship between the presence of macrophages and gigantic cells in the tissue and UHMWPE wear debris. However, just a few of these reports have considered the surface chemistry degradation caused by the UHMWPE oxidation under stressing aging procedures and the biological tissue response. In this sense, these results have contributed with some new information about the role of the biomaterial oxidized surface in the inflammatory process response, which can be valuable as a biocompatibility assay.

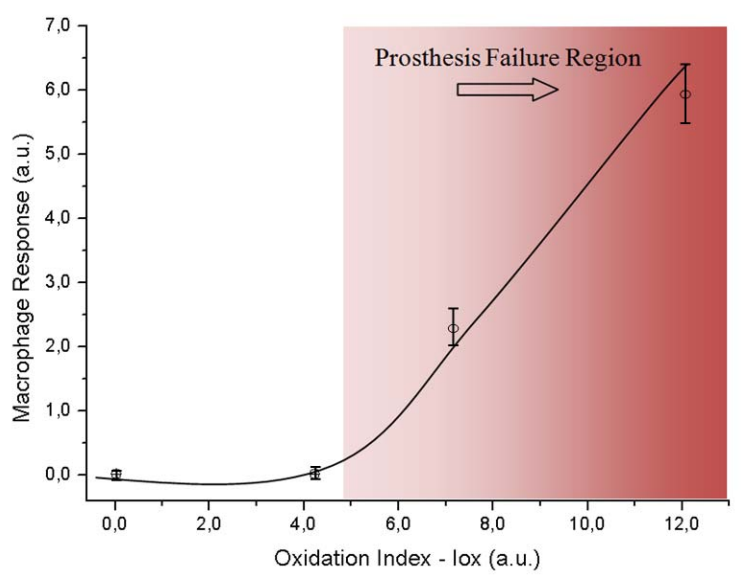

Fig. (3). Evolution of Macrophage Response as a function of the Oxidation Index $\left(\mathrm{I}_{\mathrm{ox}}\right)$.

\subsubsection{Macrophage Cell Adhesion-Spreading Assay}

In Fig. (4A) it is showed the SEM image of the reference control cells. It can be observed some of their morphological features such as the rounded shape and the presence of lamellipodia usually found on healthy cells from peritoneal macrophage cultures [24]. 

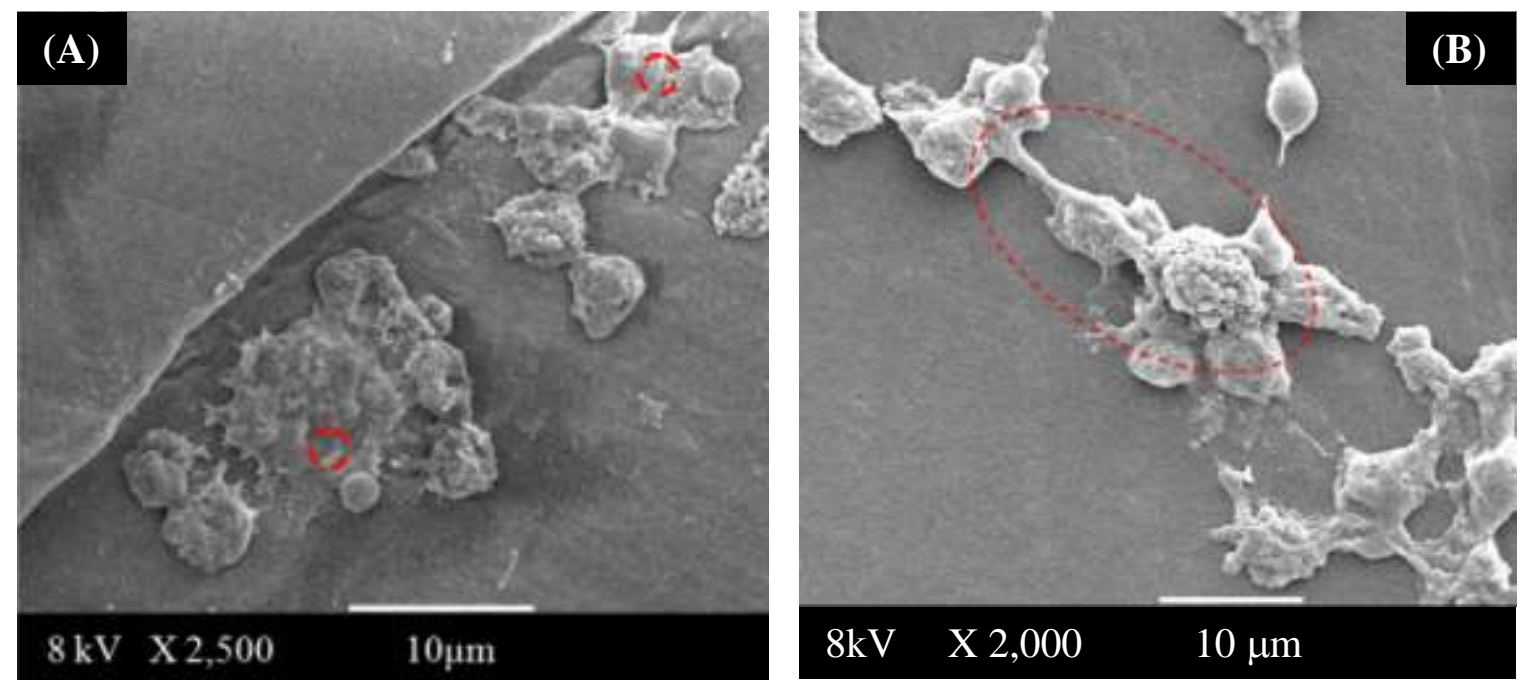

Fig. (4). (A): SEM image of reference UHMWPE used as assay control, showing rounded shape for the peritoneal macrophage cultures (at 2,500 X magnification).

(B): SEM image of UHMWPE-Ox after 90 days, showing lamellipodia and overall shape for the peritoneal macrophage cultures (at 2,000 X magnification).

Fig. (4B) shows the SEM image of UHMWPE-Ox after 90 days, where multinuclear giant cells were observed for the peritoneal macrophage cultures on the UHMWPE oxidized surfaces. The cells evidenced a very different cell shape from the control and from non-oxidized UHMWPE: the macrophages adhered and the majority has showed some aspects that indicate lamellipodia and spreading. These are common characteristics compatible with the cell activation mechanism.

A similar behavior was observed for UHMWPE samples submitted to longer aging times, for instance 120 days. Hence, it is reasonable to assume that these results have provided strong evidence that macrophage response was specifically affected by the chemical surface of UHMWPE. These findings are endorsed by the literature [25] where it was reported that there is a direct effect of the UHMWPE surface oxidative status on the polymorphonuclear granulocytes (PMN) and, therefore, cell activation of human granulocytes has been considered an indicator in the risk assessment of biopolymer-mediated inflammation. Moreover, Bosseti et al [24] state that oxidation of UHMWPE leads to a formation in the polymer chain of hydroperoxides, which can in turn produce secondary products, such as ketones and carboxylic acids. The presence of these chemical groups can induce a slight increase in the surface polarity, thus a slight increase in hydrophilicity can be expected affecting the attachment of the cells.

\section{CONCLUSIONS}

The present study has given important evidence that macrophage cell morphology and their responses were affected by the UHMWPE surface chemical modification caused by an accelerated aging mechanism. It can be assumed that the accelerated degradation assay conducted on UHMWPE samples has resulted on the formation of chemical moieties onto the polymeric surfaces which has induced detectable macrophage morphology alterations. In addition, the UHMWPE oxidation index results based on the accelerated aging assays have proven to be a very good tool on evaluating the overall degradation of UHMWPE which was correlated to the macrophage response via NO production.

Therefore, it opens a window of opportunity for estimating and monitoring the potential UHMWPE oxidation and inflammatory response, consequently improving the longevity of the prosthesis. This study has evolved a step further toward a better understanding of that rather complex system.

\section{ACKNOWLEDGEMENTS}

This work was financially supported by FAPEMIG, CAPES and CNPQ. The authors would like to thank Ticona Engeneering Polymer for kindly donating the UHMWPE polymer.

\section{REFERENCES}

[1] J. D. Desjardins, B. Burnikel, and M. Laberge, "UHMWPE wear against roughened oxidized zirconium and $\mathrm{CoCr}$ femoral knee components during force-controlled simulation," Wear, vol. 264, no. 3-4, pp. 245-256, Feb. 2008.

[2] F. Renò, and M. Cannas, "UHMWPE and vitamin E bioactivity: An emerging perspective," Biomaterials, vol. 27, no. 16, pp. 30393043, June 2006.

[3] A. W. Lee, P. J. Santerre, and E. Boynton, "Analysis of released products from oxidized UHMWPE incubated with hydrogen peroxide and salt solutions," Biomaterials, vol. 21, no. 8, pp. 851861, April 2000.

[4] Y. Sawae, A. Yamamoto, and T. Murakami, "Influence of protein and lipid concentration of the test lubricant on the wear of UHMWPE," Tribol. Int., vol. 41, no. 7, pp. 648-656, July 2008.

[5] V. Medhekar, R. W. Thompson, A. Wang, and W. Grant McGimpsey, "Modeling the oxidative degradation of UHMWPE," J. Appl. Polym. Sci., vol. 87, no. 5, pp. 814-826, Jan. 2003.

[6] P. Taddei, S. Affatato, C. Fagnano, and A. Toni, "Oxidation in ultrahigh molecular weight polyethylene and cross-linked polyethylene acetabular cups tested against roughened femoral heads in a hip joint simulator," Biomacromolecules, vol. 7, no. 6 , pp. 1912-1920, June 2006.

[7] J. Medel, F. García-Alvarez, E. Gómez-Barrena, and J. A Puértolas, "Microstructure change of extruded UHMWPE after 
gamma irradiation and shelf-aging," Polym. Degrad. Stab., vol. 88, no. 3, pp. 435-443, June 2005

[8] B. M. Willie, R. D. Bloebaum, S. Ashrafi, C. Dearden, T. Steffensen, and A. A. Hofmann, "Oxidative degradation in highly cross-linked and conventional polyethylene after 2 years of realtime shell aging," Biomaterials, vol. 27, no. 10, pp. 2275-2284, April 2006.

[9] V. S. Medhekar, "Modeling and simulation of oxidative degradation of UHMWPE," M.S. thesis, Worcester Polytechnic Institute, Worcester, MA, USA, 2001.

[10] N. C. Billingham, and M. N. Grigg, "The kinetic order of decomposition of polymer hydroperoxides assessed by chemiluminescence," Polym. Degrad. Stab., vol. 83, no. 3, pp. 441451, March 2004.

[11] M. F. G. Rocha, A. A. P. Mansur, and H. Mansur, "Characterization and accelerated ageing of UHMWPE used in orthopedic prosthesis by peroxide," Materials, vol. 2, no. 2, pp. 562-576, May 2009.

[12] M. D. Berner, M. E. Sura, B. N. Alves, and K. W. Hunter Jr., "IFN$\gamma$ primes macrophages for enhanced TNF- $\alpha$ expression in response to stimulatory and non-stimulatory amounts of microparticulate $\beta$ glucan," Immunol. Lett., vol. 98, no. 1, pp. 115-122, April 2005.

[13] H. S. Mansur, E. S. Costa Jr, A. A. P. Mansur, and E. F. B. Stancioli, "Cytocompatibility evaluation in cell-culture systems of chemically crosslinked chitosan/PVA hydrogels," Mater. Sci. Eng. C, vol. 20, no. 5, pp. 1574-1583, June 2009.

[14] J. Ma, T. Chen, J. Mandelin, A. Ceponis, N.E. Miller, M. Hukkanen, G.F. Ma, Y.T. Konttinen, "Regulation of macrophage activation," Cell Mol. Life Sci., vol. 60, no. 11, pp. 2334-2346, Nov. 2003.

[15] S. Santavirta, Y. T. Konttinen, V. Bergroth, A. Eskola, K. Tallroth, and T. S. Lindholm, "Aggressive granulomatous lesions associated with hip arthroplasty. Immunopathological studies," J. Bone Joint Surg. (Am.), vol. 72, no. 2, pp. 252-258, Feb. 1990.

[16] P. Bracco, E. M. Brach del Prever, M. Cannas, M. P. Luda, and L. Costa, "Oxidation behaviour in prosthetic UHMWPE components sterilized with high energy radiation in a low-oxygen environment," Polym. Degrad. Stab., vol. 91, no. 9, pp. 2030-2038, Sept. 2006.

[17] E. M. Brach del Prever, A. Bistolfi, P. Bracco, and L. Costa, "UHMWPE for arthroplasty: past or future?," J. Orthop. Traumatol., vol. 10, no. 1, pp. 1-8, March 2009.

[18] International Organization for Standardization, "Implants for surgery - Ultra-high-molecular-weight polyethylene (UHMWPE) Part 4: Oxidation index measurement method," Int. Organ. Stand., ISO 5834-4:2995, 2005.

[19] F. Gugumus, "Thermo-oxidative degradation of polyolefins in the solid state: Part 1. Experimental kinetics of functional group formation," Polym. Degrad. Stab., vol. 52, no. 2, pp. 131-144, May 1996.

[20] P. Bracco, V. Brunella, M. Zanetti, L. Costa, and M. P. Luda, "Stabilisation of UHMWPE with vitamin E," Polym. Degrad. Stab., vol. 92, no. 12, pp. 2155-2162, Dec. 2007.

[21] L. Costa, M. P. Luda, L. Trossarelli, E. M. Brach del Prever, M. Crova, and P. Gallinaro, "Oxidation in orthopedic UHMWPE sterilized by gamma-radiation and ethylene oxide," Biomaterials, vol. 19, no. 7-9, pp. 659-668, April 1998.

[22] M. Reggiani, A. Tinti, M. Visentin, S. Stea, P. Erani, and C. Fagnano, "Vibrational spectroscopy study of the oxidation of Hylamer UHMWPE explanted acetabular cups sterilized differently" J. Mol. Struct., vol. 834-836, pp. 129-135, May 2007.

[23] I. Eileen, and F. John, "The role of macrophages in osteolysis of total joint replacement," Biomaterials, vol. 26, no. 11, pp. 12711286, April 2005.

[24] M. Bosetti, L. Zanardi, P. Bracco, L. Costa, and M. Cannas, "In vitro evaluation of the inflammatory activity of UHMWPE," Biomaterials, vol. 24, no. 8, pp. 1419-1426, April 2003.

[25] F. Renò, F. Lombardi, and M. Cannas, "UHMWPE oxidation increases granulocytes activation: a role in tissue response after prosthesis implant," Biomaterials, vol. 24, no. 17, pp. 2895-2900, Aug. 2003.

Received: February 08, 2010

Revised: March 10, 2010

Accepted: March 13, 2010

(C) Rocha et al.; Licensee Bentham Open.

This is an open access article licensed under the terms of the Creative Commons Attribution Non-Commercial License (http://creativecommons.org/licenses/by-nc/3.0/) which permits unrestricted, non-commercial use, distribution and reproduction in any medium, provided the work is properly cited. 